\title{
Health related quality of life in children with autism spectrum disorder in Bangladesh
}

\author{
Farhana Safa and Md. Nazrul Islam \\ Department of Public Health, American International University-Bangladesh (AIUB)
}

\begin{abstract}
Background and objective: Autism spectrum disorder (ASD) is considered as an emerging problem in our socioeconomic context. The objectives of this study were to compare the health related quality of life of children with autism spectrum disorder to that of typically developing peers.

Methods: A cross sectional comparative study was conducted on autistic children and normal children in six centers of Dhaka city to see the health related quality of life from parent's perspective by using the Pediatric Quality of Life Inventory 4.0 Generic Core Scales (PedsQL scale). Total of 115 children within the age group of 8-12 years were selected, among them 57 were autistic and 58 were normal peers.

Results: Children with autism spectrum disorder had poor physical (mean score 6.04), emotional (mean score 9.77) and social (mean score 14.51) functions as well as learning ability (mean score 8.12) whereas normal children's functioning mean scores were $0.10,1.79,0.0$ and 0.45 in respective domains and the differences were significant $(\mathrm{p}<.0001)$ in each aspect of quality of life.

Conclusion: This study revealed that, children with autism spectrum disorder experienced poorer health-related quality of life than normal children and thus the findings would contribute in implementing different strategies for improving the health status of autistic children.
\end{abstract}

IMC J Med Sci 2017; 11(2): 40-44

\section{Introduction}

Autism spectrum disorder (ASD), sometimes referred to as "autism" is a chronic disorder whose symptoms include failure to develop normal social relations with other people, impaired development of communicative ability, lack of imaginative ability, and repetitive, stereotyped movements [1]. ASD affected individuals have markedly different social and emotional behaviors than non-autistic individuals. ASD also has an effect on intelligent quotient (IQ). About $30 \%$ of individuals with autism have an average or gifted IQ, while $70 \%$ are considered mentally retarded [2].

Health related quality of life in children with ASD is poor than the normally developing peers. In developing countries like Bangladesh, autism is considered as a curse. People of the society, sometimes parents are also ignorant about their children's physical and mental condition. Moreover, institutions involved with the treatment and improvement of the health of the autistic children cannot properly deal with problems associated with autism. The last decade has witnessed a significant increase in the utilization of health related quality of life (HRQL) instruments in an effort to improve patient health outcomes and to determine the efficacy of healthcare services $[3,4]$. HRQL explores the well-being of individuals with various medical conditions and disabilities. Therefore, by using this scale we can estimate the actual health condition of the autistic children (8-12

Address for Correspondence:

Dr. Farhana Safa, Lecturer, Department of Anatomy, Ibrahim Medical College, 122 Kazi Nazrul Islam Avenue, Shahbag, Dhaka, Bangladesh, Email:safa.somch@gmail.com 
years) and compare that with the normal developing child. The findings would be helpful for the effective management of autistic children. Therefore, the preset study was undertaken to find out the HRQL and socio-demographic characteristics of children with autism.

\section{Materials and Methods}

Study population and place: This comparative cross sectional study was conducted in three centers which deal with autistic children and comparison was done with normal children from three other centers. Bangladesh Protibondhi Foundation (BPF), Kalyani, Institute of Neurodevelopment and Research Centre and Society for the Welfare of the Intellectually Disabled, Bangladesh (SWID Bangladesh) and its sister wing - Ramna Protibondhi Shongstha was chosen for data collection from parent of autistic children.

Total 115 children were selected for the study. Among them 57 were autistic child and 58 were normally developing peers. The age range of both autistic and normal children was 8-12 years. In this study, children of this age group was selected because 8-12 years children are more appropriate for assessing the questions used in Pediatric Quality of Life Inventory 4.0 Generic Core Scales (PedsQL). Children with ASD were eligible to participate in the study if (a) they have one of the three ASD diagnosis e.g. autism disorder, pervasive developmental disorders not otherwise specified or Asperger disorder, (b) they are not suffering from other complicated diseases and (c) the parents of autistic child willing to provide data.

Research instrument: Data were collected from the parents (either mother or father) of the children because the autistic children could not provide the actual data that was needed and was collected by a semi-structured pre-tested interview questionnaire by considering all possible variables according to information, developed on the basis of relevant literature. The questionnaire contained sociodemographic characteristics of children and their parents along with the questions (modified) used in the PedsQL [5-8] to measure HRQL. The parents rated children's HRQL over the past month on a 5point scale ("never a problem" to "always a problem") scored from 0 to 4 with lower scores indicating better HRQL. The PedsQL comprises a physical health summary (physical health subscale8 items) and a psychosocial health summary (emotional-5 items; social-5 items; and school-5 items functioning subscales). During calculation for each child's total health summery in 4 domains, 0-4 was considered as good and above 4 was considered as poor heath function.

Procedure of data collection: Before getting started, permission for data collection was taken from every school. Data were collected from the parents at the school premises by face to face interview. The data collection for each participant required two or three visits within a 4-week period at a location of six study places. During the first visit, eligibility criteria were confirmed, and during the second visit, the PedsQL was administered. Parents or school authority were bound to provide a copy of the medical report documenting an ASD diagnosis. Healthy control children in the peer group met the same inclusion criteria except for a diagnosis of the autism spectrum. Ethical approval was obtained from institutional review board of American International University, Bangladesh (AIUB). Informed written consent was obtained from all participants and facilities involved in the study.

\section{Result}

The study was carried out among 115 children, 57 of them were autistic (ASD) and rest were normal healthy children. The ASD group comprised of 44 boys and 13 girls, with a mean age of $9.67 \pm 1.42$ years. The comparative healthy peer group comprised of 43 boys and 15 girls, with a mean age of $9.66 \pm 1.40$ years. Participating families of both groups belonged to middle to higher socioeconomic status. In autistic group, $50.9 \%$ parents had graduate and postgraduate level of education and it was $75.9 \%$ in normal group. Educational status among the respondents of normal child was higher than the respondents of autistic child. Of the total 57 respondents of autistic child group, $61.4 \%$ were housewives, $28 \%$ service holder (both govt. and private) and rests were businessman $(5.3 \%)$, unemployed, retired and agricultural worker (each 1.8\%) whereas majority $(51.8 \%)$ in control normal child group 
were service holder. Monthly family income of the all respondents ranged from $\mathrm{Tk} .10000$ to $\mathrm{Tk}$. 300,000 taka. Of the respondents of autism and normal healthy groups, $54.4 \%$ and $48.3 \%$ respectively had monthly family income of $\mathrm{Tk}$. 25001 to Tk. 50000 taka. The socio-demographic characteristics of the parents of both groups were almost similar.

Table-1 shows that the children with autism spectrum disorder had significantly higher mean scores for physical (mean 6.04), emotional (mean 9.77) and social functions (mean 14.51) as well as for learning ability (mean 8.12) compared to the normal children's mean scores which were 0.10 , $1.79,0.0$ and 0.45 in respective domains. Higher mean value of all these variables for autistic children than that of normal children indicated that autistic children had very lower quality of life.

Table-1: The mean PedsQL score of autistic and normal healthy children

\begin{tabular}{lcccc}
\hline \multicolumn{1}{c}{ Domain } & Group & $\begin{array}{c}\text { Mean } \\
\text { Score }\end{array}$ & SD & p-value \\
\hline Physical & Autistic & 6.04 & 5.281 & 0.000 \\
Health & Normal & 0.10 & 0.10 & \\
& & & & \\
Emotional & Autistic & 9.77 & 3.128 & 0.000 \\
Health & Normal & 1.79 & 1.373 & \\
& & & & \\
Social & Autistic & 14.51 & 2.861 & 0.000 \\
Health & Normal & 0 & 0 & \\
& & & & \\
School & Autistic & 8.12 & 3.601 & 0.000 \\
Health & Normal & 0.45 & 0.626 & \\
\hline
\end{tabular}

Table-2 shows that, $54.4 \%$ autistic children had poor physical function while all the children in normal group had good physical function. It was found that $94.7 \%$ autistic children had poor emotional function whereas only $3.4 \%$ of the normal children were emotionally disturbed. Table 2 further shows that, no autistic children had good social function whereas only all the normal children were socially sound. Regarding learning abilities, $82.5 \%$ autistic children had impaired or poor abilities while all the normal children had good learning function according to the pedsQL scale. In all 4 domains of pedsQL scale there was significant association of autism with poor quality of life $(p<0.0001)$.
Table-2: Status of physical, emotional and social functions as well as learning abilities of autistic and normal healthy children

\begin{tabular}{|c|c|c|c|c|}
\hline \multirow[b]{2}{*}{ Functions } & \multicolumn{2}{|c|}{ Children } & \multirow[b]{2}{*}{$x^{2}$} & \multirow[b]{2}{*}{ p-value } \\
\hline & $\begin{array}{c}\text { Autistic } \\
\text { N (\%) }\end{array}$ & $\begin{array}{c}\text { Normal } \\
\mathbf{N}(\%) \\
\end{array}$ & & \\
\hline $\begin{array}{c}\text { Physical } \\
\text { function } \\
\text { Good } \\
\text { Poor }\end{array}$ & $\begin{array}{l}26(45.6) \\
31(54.4)\end{array}$ & $\begin{array}{c}58(100) \\
0(0)\end{array}$ & 43.185 & 0.000 \\
\hline $\begin{array}{c}\text { Emotional } \\
\text { function } \\
\text { Good } \\
\text { Poor }\end{array}$ & $\begin{array}{c}3(5.3) \\
54(94.7)\end{array}$ & $\begin{array}{c}56(96.6) \\
2(3.4)\end{array}$ & 95.89 & 0.000 \\
\hline $\begin{array}{l}\text { Social } \\
\text { function } \\
\text { Good } \\
\text { Poor }\end{array}$ & $\begin{array}{c}0(0) \\
57(100)\end{array}$ & $\begin{array}{c}58(100) \\
0(0)\end{array}$ & 115.0 & 0.000 \\
\hline $\begin{array}{l}\text { Learning } \\
\text { ability } \\
\text { Good } \\
\text { Poor } \\
\end{array}$ & $\begin{array}{l}10(17.5) \\
47(82.5)\end{array}$ & $\begin{array}{c}58(100) \\
0(0) \\
\end{array}$ & 80.88 & 0.000 \\
\hline
\end{tabular}

\section{Discussion}

The Center for Disease Control and Prevention states that the prevalence of autism is increasing at epidemic rates [9]. For decades since first described by Leo Kanner in 1943, autism was believed to occur at a rate of $4-5$ per 10,000 children [10]. From surveys done between 1966 and 1998 in 12 countries (e.g., United States, United Kingdom, Denmark, Japan, Sweden, Ireland, Germany, Canada, France, Indonesia, Norway, and Iceland), the prevalence ranged from $0.7-21.1 / 10,000$ population, with a median value of $5.2 / 10,000$ (or 1/1923) [11]. The most recent results from the Centers for Disease Control and Prevention (CDC) suggest that, in the United States, the prevalence of ASD is $1 / 70$ boys and $1 / 315$ girls, yielding an overall rate of $1 / 110$ [9]. This is nearly identical to the overall prevalence from a recent British study [12]. In our country it has been reported that out of every 94 boys, one is affected by autism. For girls, it is one in every 150. In Bangladesh, no systematic research has been carried regarding the magnitude or prevalence of autism but it is assumed that about 300,000 children are affected [13]. 
Previous studies related to HRQOL of autistic children tried to find out the agreement between children self and parent's proxy report as well as children's QOL and result revealed lower QOL of autistic group than normal peers. In this study, we have used the data from parent's perspective. This study set out to increase our knowledge of children with ASD's HRQL compared to typically developing peers from the parents' perspective. The study revealed significantly poorer HRQL for children with ASD than their peers for the physical, emotional, social functions as well as learning ability at school. Children with ASD had consistently poor performance in those parameters. In relation to HRQL parameters it appeared that the children with ASD had lower well-being, which should be addressed by service providers. This confirms previous findings in children and adolescents with ASD and high functioning autism (HFA), but uses a control group of typically developing children instead of normative data [5,7,14-17].

ASD has been and continues to be a major health issue in our current society. Significant numbers of children are being diagnosed with ASD each year, and this includes young adults, indicating a need to increase the understanding and awareness of the general public. This study would help the policy makers and administrators to find out the actual condition of autistic children in comparison to normal one and thus would contribute in implementing different strategies for improving health status of autistic children.

\section{References}

1. Carlson NR, editor. Physiology of Behavior. 9th ed. United States of America; Pearson Education Inc.publisher; 2007.

2. Sarason IG, editor. Abnormal psychology: the problem of maladaptive behavior. Upper Saddle Rivery, New Jersey; Pearson Education Inc.publisher; 2002.

3. Matza LS, Swensen AR, Flood EM, Secnik K, Kline Leidy N. Assessment of health-related quality of life in children: A review of conceptual, methodological and regulatory issues. Value Health. 2004; 7(1): 79-92.
4. Varni JW, Burwinkle TM, and Lane MM. Health-related quality of life measurement in pediatric clinical practice: An appraisal and precept for future research and application. Health and Quality of Life Outcomes. 2005; 3: 34-43.

5. Kuhlthau K et al. Health-Related Quality of Life in children with autism spectrum disorders: results from the autism treatment network. Journal of autism and developmental disorders. 2010; 40(6): 721-729.

6. Sheldrick RC, Neger EN, Shipman D. Quality of life of adolescents with autism spectrum disorders: concordance among adolescents' self-reports, parents' reports, and parents' proxy reports. Quallty of Life. 2011; 21(1): 53-57.

7. Shipman DL, Sheldrick RC. Quality of life in adolescents with autism spectrum disorders: reliability and validity of self-reports. Journal of Development Behavior Paediatric. 2011; 32(2): 85-89.

8. Limbers CA, Heffer RW, Varni JW. HealthRelated Quality of Life and Cognitive Functioning from the Perspective of Parents of School-Aged Children with Asperger's Syndrome Utilizing the PedsQL (TM). Journal of Autism and Developmental Disorders. 2009; 39(11): 1529-1541.

9. Rice C. Prevalence of autism spectrum disorders-Autism and Developmental Disabilities Monitoring Network MMWR Surveillence Summary. Autism Development and Disability Monioring Network Surveillence Year 2006. 2009; 58: 1-20.

10. Kanner L. Autistic disturbances of affective contact. Nerv. Child. 1943; 2: 217-250.

11. Fombonne E. The epidemiology of autism: A review. Psychological Medicine. 1999; 29(4): 769-786.

12. Baird G, Simonoff E, Pickles A, Chandler S, Loucas $T$, Meldrum D. Prevalence of disorders of the autism spectrum in a population cohort of children in South Thames: the Special Needs and Autism Project (SNAP). Lancet. 2006; 368(9531): 210-215. 
13. "Autistic children's welfare foundation." [Online]. Available: http://www.acwf-bd.org/ about_us.php.

14. Kamp-Becker I, Schröder J, Remschmidt H, Bachmann CJ, Schroder J. Health-related quality of life in adolescents and young adults with high functioning autism-spectrum disorder. German medical science: Psycho Social Medicine. 2010; 7: 1-10.

15. Bastiaansen D, Koot HM, Ferdinand RF, Verhulst FC. Quality of Life in Children With Psychiatric Disorders: Self-, Parent, and Clinician Report. Journal of the American
Academy of Child \& Adolescent Psychiatry. 2004; 43(2): 221-230.

16. Kamp-Becker I, Schröder J, Muehlan H, Remschmidt $\mathrm{H}$, Becker $\mathrm{K}$, Bachmann $\mathrm{CJ}$. Health-related quality of life in children and adolescents with Autism Spectrum Disorder. Zeitschrift für Kinder-und Jugendpsychiatrie und Psychotherapie. 2011; 39(2): 123-131.

17. Lee LC, Harrington RA, Louie BB, Newschaffer CJ. Children with autism: Quality of life and parental concerns. Journal of Autism and Developmental Disorders. 2008; 38(6): 1147-1160. 